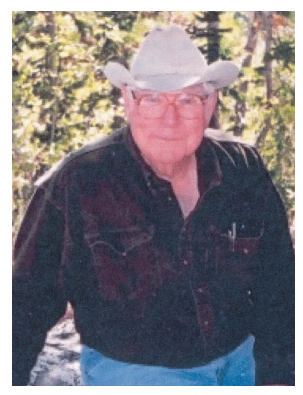

Thad Box

\title{
The Power of Story
}

\section{Listening to the Land}

Story is the umbilical cord between the past, present and future. - Terry Tempest Williams

Seek ye the counsel of the aged, for their eyes have looked on the faces of the years and their ears have harkened to the voices of Life. -Kahlil Gibran

I always wanted to be a forest ranger. When I was quite young, I was privileged to spend some time with a real bonafide Forest Ranger Hamner Christensen in his surroundings. Joel Frandsen

With this issue of Rangelands we celebrate the 100th Anniversary of the US Department of Agriculture Forest Service. This event is described with statistics, tributes, and listings of accomplishments. That many of those contributions were made by range people reminds us again of the parallel development between the Forest Service and our profession.

That relationship is best told by stories that nourish the old and inspire the young. Terry Tempest Williams, in a 2002 interview, said "Quite simply, the source [of stories] is life. Day to day, day by day. I never stop being amazed by the simple, raw, true power of life." Later, she said, "Story bypasses rhetoric and pierces the heart. We feel it. Stories have the power to create social change and inspire community."

The life story of Hamner Christensen inspired young Joel Frandsen. The story continues, through those who know Joel, to influence land management far beyond the Forest Service. This process is as old as civilization itself. Stories by elders mold the future. It is from elders that each new generation gets its values. Stories define who we are and why we exist.

I was a young professor when I first met W. R. Chapline. I was surprised and impressed when a hero of our profession took a bus seat next to me on a range tour. He said folks called him "Chappie." Could anyone call an icon that? Certainly not I. With each passing landscape, Mr Chapline told a new story: how Gifford Pinchot was persuaded to allow grazing on national forests, how early research tried to estimate carrying capacity, how goats were once an important part of oak control in southwestern forests.

I asked him to talk to my class about early research. When he entered the room, he carried a copy of The Western Range. He didn't talk about research. Instead he launched into a story of how and why the publication came about. Students learned that day how politics of agencies determined who would manage America's public lands. And they were introduced to Forsling, Campbell, and other early range stalwarts, not as biologists, but as politicians.

Bill Hurst's memoir, $A$ Life Recalled, offers stories of a generation when there was only one ranger on the Manila Ranger District. He was truly a multiple-use specialist, doing all the necessary work on the forest. Joel Frandsen's Forest Trails and Tales humorously examines the 
work of another generation of range managers. It is from stories like these, not official reports, that values of our profession emerge. They show that our profession is not a job, but the dedication of a life to an ideal. And those stories, told to or read by me, become part of who I am.

I don't like to think I am one of the old folks. Most of my life I have been a youngster among my peers-the youngest graduate, youngest professor, youngest dean, youngest whatever. But statistics show I am almost two years past the average life expectancy for an American male. Records show I have been a member of SRM 48 years-longer than the average age of our members. Data tell me I am older than I feel.

I am, whether I like it or not, one of the elders. Destiny made me one of the keepers of our collective memory-a storyteller. People of my generation, and those older, are blessed (or maybe cursed) to be guardians of our values and traditions. Our role is to pass these to the young in such a way that new generations minimize mistakes as they work in a rapidly changing world. We serve best when we stick to principles.

We older folks have a difficult job. Success depends on how well we can adjust to being elders, relinquishing control and passing the reins to those with energy and stamina who work in a world much different than it was even a decade ago. It depends on how well we resist meddling in details

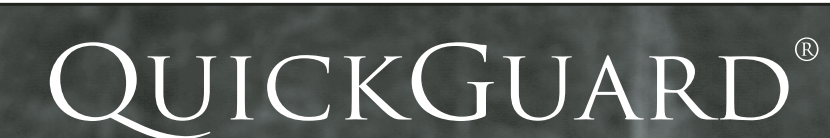
Sterile Triticale Hybrid

Stabilize soil with QuickGuard ${ }^{\circledR}$ Sterile Triticale

- Non-reseeding annual provides superior quick cover

- Large root mass and upright growth stabilize soil and protect developing native perennials

- Cold tolerant, drought tolerant, adapted to a wide range of soil and moisture conditions

- Hardy \& durable, but not persistent or invasive
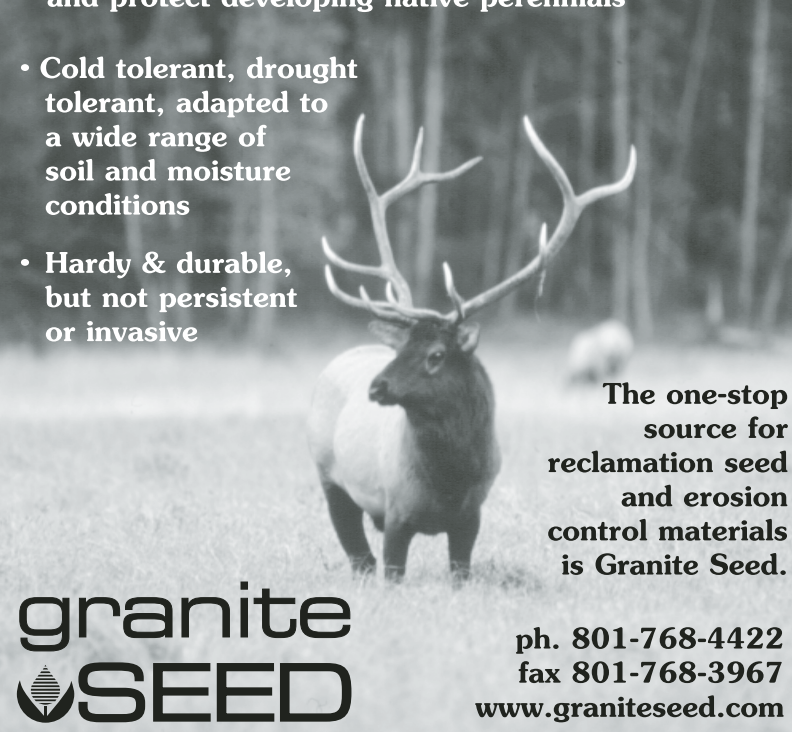

ph. 801-768-4422

fax 801-768-3967 www.graniteseed.com which we are often ill-equipped to handle.

Our role is not to preach. Or to insist the old way is best. Not only may it not be best, it may not even be applicable in today's environment. Teachers should be like those described by Gibran:

If he is indeed wise he does not bid you enter the house of his wisdom, but rather leads you to the threshold of your own mind...

For the vision of one man lends not its wings to another man.

And even as each one of you stands alone in God's knowledge, so must each one of you be alone in his knowledge of God and his understanding of earth. - Khalil Gibran, The Prophet

Young professionals are often lacking in their understanding of the earth. Their comprehension can be enhanced by research much improved over that of Chapline's day. It is guided by science that is much better than was available to me. But it is elders who prevent the young from standing alone. We are storytellers, not rulers demanding the young do as we did. Our stories lead the next generation to think about principles and involve those principles in their work.

It has been said that range management is both an art and a science. The science comes from experiments, carefully designed, implemented, analyzed, and stored in the written record. Application of science is by people actively involved with land use. The art comes from experience. Elders pass their interpretations of history, their demonstrations of professionalism, and their understanding of why we exist through story.

We understand the first 100 years of the Forest Service mainly through life stories of the people who had the vision, did the work, served the land. We understand our profession because of lives lived, not ranges deferred, shrubs planted, or erosion controlled. A day with $\mathrm{Mr}$ Chapline changed my understanding of the Forest Service-and my profession-forever.

Stories of people who lived long before range management had a name are equally important. Fred Provenza, at the Salt Lake meeting, quoted Buddha, the Sutras, the Dalai Lama, and Sun Zui in developing his thesis that "...creativity comes from the union of pairs of opposites, as each polarity ceaselessly dies to itself and resurrects anew." He captured wisdom of elders from many cultures and generations to challenge us to think about change and sustainability. He warned that with each generation our profession must be born anew.

Science provides tools. Institutions provide organization. But stories analyze deaths and resurrections, promote rebirth into a changed world. They form the basis for change. They point us to the future. They inspire us to go there. They define who we are. They suggest who we can become.

Never underestimate the power of story. 